\title{
Intoxicación por Brugmansia arborea (Solanaceae) en un canino
}

\author{
Sosa, S. '; Ingold, A. ; Delucchi, L. '; García, C. \\ 'Área de Toxicología, ${ }^{2}$ Departamento de Clínica y Patología de Pequeños Animales, Facultad de Veterinaria, \\ Universidad de la República, Montevideo 11600, Uruguay. Teléfono 5986287672. \\ E-mail: santiagososa582@gmail.com
}

\begin{abstract}
Resumen
Sosa, S.; Ingold, A.; Delucchi, L.; García, C.: Intoxicación por Brugmansia arborea (Solanaceae) en un canino. Rev. vet. 28: 2, 165-167, 2017. Los animales de compañía pueden ser víctimas de intoxicaciones de diferente origen, constituyendo las plantas un $10-15 \%$ de las etiologías reportadas. Brugmansia arborea sin. Datura arborea (floripondio, trompeta de ángel) es un arbusto o árbol pequeño, perenne, con flores blancas, cónicas y pendulares, que se encuentra distribuido mundialmente, utilizándose como planta ornamental en jardines. El género Brugmansia posee un alto contenido de alcaloides del tropano como escopolamina, hiosciamina y atropina, que antagonizan las acciones de la acetilcolina y los receptores colinérgicos muscarínicos. En la bibliografía se encuentran documentados numerosos casos de intoxicación por esta planta en seres humanos, provocando un síndrome anticolinérgico, parálisis flácida, convulsiones y muerte. En el presente trabajo se describe por primera vez el diagnóstico de un caso de intoxicación por Brugmansia arborea en un perro de dos meses de edad. Se describen los signos clínicos observados y su correlación con los reportados en casos humanos.
\end{abstract}

Palabras clave: perro, intoxicación, escopolamina, Brugmansia arborea (trompeta de ángel).

\begin{abstract}
Sosa, S.; Ingold, A.; Delucchi, L.; García, C.: Intoxication by Brugmansia arborea (Solanaceae) in a dog. Rev. vet. 28: 2, 165-167, 2017. Among the etiologies of poisoning in companion animals, plants represent $10-15 \%$ of the agents reported. Brugmansia arborea sin. Datura arborea (floripondio, angel's trumpet) is a shrub or small tree, perennial, with white, conical and pendulous flowers, distributed worldwide as an ornamental plant in gardens. Brugmansia genus present high content of tropane alkaloids such as scopolamine, hyoscyamine and atropine, which antagonize acetylcholine at cholinergic muscarinic receptors. Documented cases of human poisoning with this plant are numerous and are characterized by an anticholinergic syndrome, flaccid paralysis, seizures and death. In this report the first case of Brugmansia arborea poisoning in a two-month old dog is reported. The clinical signs observed and their correlations with those reported in human cases are presented.
\end{abstract}

Key words: dog, poisoning, scopolamine, Brugmansia arborea (angel's trumpet).

\section{INTRODUCCIÓN}

Los animales de compañía pueden ser víctimas de intoxicaciones de diferente origen, ya sea por plaguicidas, medicamentos, productos de limpieza, aditivos, venenos, así como también por plantas tóxicas. Dentro de las posibles etiologías, las plantas juegan un rol importante, constituyendo aproximadamente el $10-15 \%$ de las mismas. La toxicidad de las plantas depende de diferentes factores: especie, época del año, cantidad y parte ingerida (flores, hojas, raíces y semillas), siendo ello determinante en la gravedad de los signos clínicos observados ${ }^{5}$.

Recibido: 25 noviembre 2016 / Aceptado: 23 mayo 2017
En su entorno, los animales pueden tener acceso a diferentes tipos de plantas. Esta facilidad, sumada al desconocimiento del potencial tóxico por parte de los responsables de los animales, permite que los casos de intoxicación sean frecuentes. Una de las principales dificultades en el diagnóstico radica en la identificación de la especie botánica en cuestión. Una misma planta puede presentar diferentes nombres vulgares en la misma región, por ello, contar con el nombre científico de la especie involucrada es fundamental para el diagnóstico, tratamiento y pronóstico en cada caso ${ }^{5,7}$.

Brugmansia arborea sin. Datura arborea (floripondio, estramonio o trompeta de ángel) pertenece a la familia Solanaceae. Es un arbusto o árbol pequeño, perenne, con flores blancas, cónicas y pendulares. Se 
encuentra distribuido principalmente en América del Sur, aunque su presencia también se ha descrito en Europa, América del Norte y Australia ${ }^{1,3}$. En Uruguay es comúnmente utilizada en jardines como planta ornamental.

El género Brugmansia, junto con los géneros $D a$ tura e Hyoscyamus, posee un alto contenido de alcaloides del tropano como escopolamina, hiosciamina y atropina ${ }^{4,8}$. Los alcaloides del tropano antagonizan las acciones de la acetilcolina y los receptores colinérgicos muscarínicos. Esto afecta directamente al sistema nervioso autónomo, actuando sobre el corazón, sistema digestivo y sistema nervioso central ${ }^{3,4}$.

En seres humanos su ingestión puede ocasionar depresión, alteraciones de comportamiento, debilidad, taquicardia, midriasis, sequedad de las membranas mucosas, estreñimiento y en casos graves, insuficiencia respiratoria. La intoxicación grave puede provocar parálisis flácida, convulsiones y muerte ${ }^{1,3,4}$. Otros signos neurológicos que se han descrito son anisocoria y síndrome de Guillain-Barré fulminante, con neuropatía axonal motora aguda ${ }^{9}$. Se ha reportado un caso de auto-mutilación en un joven, con graves efectos ${ }^{6}$.

Los alcaloides se encuentran distribuidos en toda la planta, encontrándose en mayor concentración en flores y hojas ${ }^{8}$. La ingestión de flores o una infusión de flores y hojas, tiene como resultado un síndrome anticolinérgico del sistema nervioso central caracterizado por fiebre, delirio, alucinaciones, agitación, alteración persistente de la memoria, incoherencia y comportamiento agresivo, así como también daños cardíacos, midriasis, vómitos y otros signos vegetativos ${ }^{4}$.

En cuanto al tratamiento, está descrito que la administración de fisostigmina intravenosa contribuye a revertir los efectos tóxicos del síndrome anticolinérgico $^{1,4,6,9}$. Especies de Brugmansia han sido empleadas por chamanes durante cientos de años en los Andes y en la región oeste del Amazonas para tratar enfermos, así como utilizadas en rituales religiosos, debido a sus efectos alucinógenos y para alterar los estados de la conciencia ${ }^{8}$. En seres humanos el abuso de esta planta y sus efectos tóxicos han sido reportados desde hace cuarenta años ${ }^{9}$. En Uruguay se reportó la intoxicación accidental de un niño por ingestión de hojas de esta planta. En dicho caso, el paciente presentó fiebre, irritabilidad, agitación, convulsiones y enterocolitis, recuperándose luego de cinco días ${ }^{2}$.

En el presente trabajo se describe por primera vez un caso de intoxicación por Brugmansia arborea en un perro.

\section{MATERIAL Y MÉTODOS}

Un canino, macho, raza Rotweiler, de dos meses de edad, ingresó al Hospital de la Facultad de Veterinaria, Universidad de la República (Uruguay). El motivo de consulta fue la aparición aguda de vómitos, al menos dos convulsiones en las últimas 12 horas y depresión. Durante la anamnesis el propietario manifestó que pre- vio al comienzo de los signos, el cachorro había estado jugando en un jardín y comiendo algunas de las plantas ornamentales allí presentes. A la consulta fueron traídas muestras de hojas y flores de dichas plantas, las cuales se remitieron al Laboratorio de Botánica de la Facultad de Química de dicha universidad, para su identificación.

Durante el examen clínico el animal se presentó decúbito lateral y estupor. La temperatura fue de $38^{\circ} \mathrm{C}$ y las frecuencias cardíaca y respiratoria de 125 y 44 por minuto respectivamente. Las mucosas oral y ocular eran normocrómicas y el tiempo de llenado capilar fue de 2 segundos. Se pudo constatar una leve deshidratación.

$\mathrm{Al}$ examen neurológico el animal presentó estupor y períodos de agitación. Las pupilas se presentaron del mismo tamaño, pero el reflejo pupilar, directo y consensuado, se encontraba ausente. Durante la consulta el animal realizó vocalizaciones periódicas, movimientos repetidos de los miembros anteriores y presentó una convulsión tónico-clónica. Se efectuaron pruebas diagnósticas que incluyeron hemograma completo, bioquímica sanguínea, ecografía de abdomen y radiografía de tórax. El tratamiento instaurado fue de sostén, administrándose suero salino intravenoso $50 \mathrm{ml} / \mathrm{kg} / \mathrm{día}$ y diazepam $0,5 \mathrm{mg} / \mathrm{kg}$ cada seis horas.

\section{RESULTADOS}

Las muestras de las plantas fueron clasificadas como Brugmansia arborea MVFQ 4371, nombre común floripondio, estramonio o trompeta de ángel, miembro de la familia Solanaceae.

El hemograma completo y la bioquímica sanguínea realizadas no manifestaron alteraciones, así como tampoco la ecografía abdominal y la radiografía de tórax.

Un día después de iniciado el tratamiento, el animal se encontraba consciente y no repitió las convulsiones. Al segundo día, se mostró alerta y fue dado de alta.

\section{DISCUSIÓN}

En el presente caso se observaron convulsiones, estupor y alteración de la conciencia, signos clínicos que coinciden con los reportados en las intoxicaciones en seres humanos por la ingestión de Brugmansia $s p^{1,4}$. Se han citado otros signos no descritos en personas, como la disminución del reflejo pupilar y un signo que no tiene correlación específica con el ser humano, como son las vocalizaciones.

Es importante destacar que la gravedad de los signos clínicos depende de la concentración de alcaloides ingeridos, los cuales pueden incluso provocar la muerte ${ }^{1,3,6}$. En este caso, la cantidad ingerida por el animal fue tal que le produjo los signos antes descritos, pero no lo muerte.

En conclusión, los signos clínicos observados y el reconocimiento de la muestra botánica, permitieron confirmar que el animal se intoxicó por la ingestión de 
flores y hojas de Brugmansia arborea, siendo este el primer caso reportado en caninos.

\section{REFERENCIAS}

1. Barreto SA, Guzmán J, Gutiérrez JC. 2016. Intoxicación por uso recreativo de 'floripondio', reporte de caso. Rev Med Risaralda 22: 68-70.

2. Bauza CA, Matteo AL. 1962. Poisoning by Datura arborea (L.) ("floripon"). Histopathological study of the gastric and rectosigmoid mucosa by aspiration biopsy. Arch Pediatr Urug 33: 14-8,

3. Göpel C, Laufer C, Marcus A. 2002. Three cases of angel's trumpet tea-induced psychosis in adolescent substance abusers. Nord J Psychyatry 56: 49-52.

4. Hall RC, Popkin MK, McHenry LE. 1977. Angel's trumpet psychosis: a central nervous system anticholinergic syndrome. Am J Psychiatry 134: 312-314.
5. Iramain MS, Herrero MA, Volpe SM, Toro SE. 2008. Plantas ornamentales tóxicas: guía para el diagnóstico, tratamiento y prevención de las intoxicaciones en pequeños animales, Edit. BM Press, Buenos Aires, p. 21-28.

6. Marneros A, Gutmann P, Uhlmann F. 2006. Self-amputation of penis and tongue after use of angel's trumpet. Eur Arch Psychiatry Clin Neurosci 256: 458-459.

7. Milewski LM, Safdar AK. 2006. An overview of potentially life-threatening poisonous plants in dogs and cats. $J$ Vet Emerg Crit Care 16: 25-33.

8. Rosés OE, Lopez CM, Garcia JC. 1987. Aislamiento e identificación de alcaloides del tropano en especies del género Brugmansia (Solanaceae). Acta Farm Bonaerense 6: 167-174.

9. Sevketoglu E, That B, Tugcu B, Demirelli Y, Hatipoglu S. 2010. An unusual cause of fulminant Guillain-Barré syndrome: angel's trumpet. Pediatr Neurol 43: 368-370. 